\title{
Psychiatric Referrals in a Multidisciplinary Teaching Hospital
}

\author{
Senilo Magh ${ }^{1}$, Lalhriatpuia ${ }^{2}$, Sahana $\mathrm{N}^{3}$, Laishram Chingkheileima ${ }^{4}$, \\ N Heramani Singh ${ }^{5}$ \\ 1,2,3,4 - Junior Residents,5-Professor and Head of Department, \\ Department Of Psychiatry \\ Regional Institute Of Medical Science, Imphal, Manipur
}

\begin{abstract}
Background:There is a dearth of studies which have focused on consultation-liaison psychiatry in India.. Data from the previous studies have suggested that the referral rates in India are very low considering the higher psychiatric morbidity rates.

Objectives:The aim of the study is to assess the magnitude and the pattern of Psychiatric referrals and to find out the scope and difficulties of Consultation Liaisons.

Materials and Methods: All inpatient referred to Psychiatry department over a period of one year (i.e. April 2014-March 2015). The data were taken and analysed in terms of socio-demographic characters, referring unit, reasons for referral and psychiatric diagnosis.

Results:A total of 191 inpatients were referred for psychiatric opinion comprising $0.40 \%$ of total indoor admission. $102(53.4 \%)$ referrals were from Medicine and related specialities followed by Surgery and related Specialities (19.89\%). The commonest reason for referrals was irrelevant talks and other Psychotic features (29.84\%), followed by Deliberate Self Harm and attempted suicide (20.41\%), however the most common final diagnosis was Substance Use Disorder (30.36\%) followed by Mood Disorder (20.41\%). Male consist of 58.11\% and majority of the referred patient belongs to Middle socio-economic status.
\end{abstract}

Keywords: Psychiatry referrals, Consultation - liaison psychiatry

\section{Introduction}

Medical practitioners commonly encounter patients who present with symptoms that cannot be explained medically, for which no organic cause can be found, or symptoms they suspect are feigned for primary or secondary gain. The consultation-liaison services in India follow the consultation model, wherein a psychiatrist evaluates and manages the patient who is referred from a physician/surgeon ${ }^{[1]}$. There is a dearth of studies which have focused on consultation-liaison psychiatry in India. Data from the previous studies have suggested that the referral rates in India are very low $(0.06 \%-3.6 \%)$, considering the higher psychiatric morbidity rates $(18.42 \%-53.7 \%)$ which have been reported in the studies that have screened patients in other departments for psychiatric morbidity ${ }^{[2,3]}$. There is convincing evidence that psychosocial factors have a major impact on both patient outcome and the cost of medical-surgical services of general hospitals ${ }^{[4]}$. These psychosocial factors are either not detected by general medical practitioner or they are identified and address late $^{[5]}$. The coexistence of psychiatric and medical problems in patient usually leads to more complex diagnostic assessments, increased health care costs and less satisfactory outcome ${ }^{[5]}$. With this background, a study of psychiatric referrals was conducted, with the objective of assessing the profile of referred patients, source of referral, reason for referral and the psychiatric diagnoses.

\section{Materials And Methods}

The study was done in a multi-speciality teaching cum tertiary care hospital situated in Imphal, Manipur with 1032 indoor beds and an indoor facility for Psychiatry department. The study included all the consecutive indoor patients referred from different department during 1 year period from April, 2014 to March 2015. It is a retrospective study with the aims to know the socio-demographic characteristics and the reason for referral, to study the magnitude and the pattern of psychiatric referrals. ICD 10 (the International Classification of Diseases, $10^{\text {th }}$ version, Classification of Mental and Behavioral Disorders) was used to diagnose the referred cases.

\section{Results}

A total of 191 inpatients referrals were seen by Psychiatry Department during the 1 year period between April 2014 to March 2015. Out of the total 47,088 patients admitted in the hospital during this period, only $191(0.40 \%)$ inpatients were referred for Psychiatry Consultation. The average age of the patient was 41.88 years with the age range being 9 to 92 years. Majority of the patient i.e. 145(75.91\%) belonged to the adult age 
group while children and adolescent and elderly patient were $9.4 \%$ and $14.66 \%$ respectively. Male consist of $58.11 \%$ and majority of the referred patient belongs to Middle socio-economic status.

Department wise referrals

The major sources of referrals were from Medicine $(102,53.4 \%)$ and related specialities followed by Surgery and related Specialities $(38,19.89 \%)$. The referralrate from other and minor disciplines was very low (Table 1).

Table No. 1. Department wise referrals and percentages

\begin{tabular}{|c|l|c|c|}
\hline Sl.No & \multicolumn{1}{|c|}{ Department } & No. of Referrals & \% \\
\hline 1. & Medicine and related specialities & 102 & 53.4 \\
\hline 2. & Surgery and related specialities & 38 & 19.89 \\
\hline 3. & PMR & 21 & 10.99 \\
\hline 4. & Orthopaedic & 17 & 8.9 \\
\hline 5. & ENT & 7 & 3.6 \\
\hline 6. & Obstetrics and Gynaecology & 6 & 3.1 \\
\hline & TOTAL & 191 & \\
\hline
\end{tabular}

\section{Reasons for referrals}

The commonest reason for referrals was acute onset irrelevant talks and other abnormal behavior in which $40.35 \%$ were diagnosed with psychotic disorder, $35.08 \%$ with Substance use Disorder and with $10.5 \%$ Mood disorder and $14.03 \%$ with organic disorder. Second, most common reason for referral was found to be Deliberate Self-harm/Suicide attempts for which 39 patients were referred. Out of this 18 patients were diagnosed as Impulsive Disorder, 15 patients were diagnosed having Depression with suicidal ideas, 2 patients were due to sudden onset psychosis and 4 patients were due to Substance use disorder. Others were referred forby Anxiety (19.89\%), followed by substance abuse and related disorder (17.8\%), Depression (9.42\%) and insomnia (2.6\%) (Table No.2).

Table No.2. Reasons for referrals

\begin{tabular}{|c|l|c|c|}
\hline Sl.No & \multicolumn{1}{|c|}{ Department } & No. of Referrals & \% \\
\hline 1. & Deliberate self-harm & 39 & 20.41 \\
\hline 2. & Irrelevant talk, psychotic behaviour & 57 & 29.84 \\
\hline 3. & Mild withdrawal & 34 & 17.8 \\
\hline 4. & Depression & 18 & 9.42 \\
\hline 5. & Anxiety & 38 & 19.89 \\
\hline 6. & Insomnia & 5 & 2.6 \\
\hline & TOTAL & 191 & \\
\hline
\end{tabular}

\section{Final Psychiatric Diagnosis}

Analysis of the final diagnosis given by Psychiatrists reveals that majority of the patients $(30.36 \%)$ had alcohol and other substance abuse/dependence disorder followed by Mood disorder (20.41\%). On the third is Anxiety and Stress related Disorder (19.89\%) followed by Schizophrenia and other Psychotic Disorder (13.08\%). Impulsive Disorder accounting for 9.4\% followed by Organic Disorder (4.18\%) and Insomnia (2.6\%) Table No. 3.

Table No. 3Final Psychiatric Diagnosis

\begin{tabular}{|c|l|c|c|}
\hline Sl.No & \multicolumn{1}{|c|}{ Department } & No. of Referrals & \% \\
\hline 1. & Substance dependence in withdrawal & 58 & 30.36 \\
\hline 2. & Anxiety and stress related disorder & 38 & 19.89 \\
\hline 3. & Mood disorder & 39 & 20.41 \\
\hline 4. & Psychotic disorder & 25 & 13.08 \\
\hline 5. & Impulsive Disorder & 18 & 9.4 \\
\hline 6. & Insomnia & 5 & 2.6 \\
\hline 7. & Organic Disorder & 8 & 4.18 \\
\hline & TOTAL & 191 & \\
\hline
\end{tabular}

\section{Discussion}

The referral rate of $0.40 \%$ of all admission in this study is comparable to other recent studies conducted in India ${ }^{[6,7]}$. Referral rate reported from the British samples have varied from $0.4 \%$ to $2.8 \%$ which is also consistent with this study and lower than those reported from US studies ${ }^{[8,9]}$. However, it is still comparable to previous Indian studies done more than three decades ago indicating that the trend has not much improved 
maybe due to an exclusive reliance of non-psychiatric faculties on a consultant centred approach and less awareness ${ }^{[10,11,12]}$.

Referral from Medicine and related specialities which is $53.4 \%$ of all referral are quite comparable as other studies in India ${ }^{[7,10,12,13]}$ and referrals from other department were low as previously reported by other Indian studies. Comorbid psychiatry problem is usually neglected because of urgency of treatment of primary surgical condition as well as lack of experiences in the field of Psychiatry ${ }^{[10,11]}$.Only $3.1 \%$ cases were referred from Gynaecology and Obstetrics Department and this ratio was also similar in the study of Dhavale HS in India, which may be due appearance of emotional disturbance during menstruation period, hormonal effect during pregnancy and Gynaecologists and Obstetricians are aware about them as normal phenomenon during pregnancy period ${ }^{[14]}$ In addition there is a lot of stigma not only among the patient but also among the health care professionals about mental illness and its treatment.

The commonest reason for referrals was acute onset irrelevant talks and other abnormal behavior $(n=57,29.84 \%)$ as comparable studies done by Peh et $\mathrm{al}^{[15]}$. Also, a lot of them were diagnosed to have Substance use Disorder which is very prevalent in the study area. The number of referrals for Deliberate selfharm/suicidal attempts were quiet high $(\mathrm{n}=39,20.41 \%)$ comparing with earlier India studies ${ }^{[11]}$ but comparable to figures seen in other studies, which showed values ranging from $9.7 \%$ to $33.14 \%{ }^{[, 16,17]}$. Deliberate selfharm/Impulsive para-suicide $(n=18)$, Depression $(n=15)$ and Substance use disorder $(n=4)$ were the commonest, second commonest and third commonest final diagnosis made respectively. It is widely perceived by public that suicidal attempts, being medico-legal cases, are better handled by the government hospitals in terms of legal formalities ${ }^{[18]}$. This, coupled with the relatively lower treatment costs in government hospitals, may have resulted in a decreased inflow of patients following suicidal attempts, to the study hospital.

Substance use was the reason for $17.8 \%$ of the total referrals. This was similar to the findings of Singh et al., ${ }^{[19]}$ which showed that $14.5 \%$ of the referrals were caused by substance use. High proportion of referrals was later diagnosed asSubstance abuse and related Disorder accounting for $30.36 \%$ of all diagnosis which is quiet high compared to earlier studies conducted in India and Asia ${ }^{[12,20,21]}$. This may be due to the easy availability and the unrest society due to lots of insurgencies. Also $20.41 \%$ were diagnosed to have Mood Disorder and 19.89\% were diagnosed as Neurotic, Stress and related Disorder. Reviewing other studies, Mood or Depressive disorder and neurotic is one of the commonest referred disorders in liaison psychiatry ${ }^{[8,13,19,22]}$. In this study males were found to be diagnosed with organic mental disorders and disorders due to substance abuse whereas females were more commonly related to neurotic and stress related disorder. Psychotic disorder were found in $13.08 \%$ of the referral and $9.4 \%$ were diagnosed as having Impulsive disorder. This finding is quiet similar as findings from recent study and younger age were more prone for showing Impulsive suicidal attempts ${ }^{[3]}$. Other diagnosis were organic Disorder (4.18\%) followed by Insomnia (2.6\%).

\section{Limitations}

There are few limitations to our study which needs to be considered while interpreting the result. The study was done among patients referred for consultation-liaison within a period of 12 months period so may not represent overall psychiatric referral. The diagnosis was made by a consultant Psychiatrist rather than the use of standardized structured interview and rating scales.

\section{Conclusion}

The present study shows that the liaison psychiatry services to a general hospital needs to improvea lot so that it can be associated with significant increase in the referral rate of patient from medical and surgical wards. A multi-disciplinary approach should be encouraged for the management of patients who attend general hospitals, in order to facilitate early recognition and management of psychiatric problems. Simultaneous treatment of both conditions may help to reduce the cost of management and possibly prevent complications. Further studies need to focus on effects of interventions, like sensitizing other specialists, especially physicians, regarding psychiatric problems and their varied clinical presentations

\section{Reference}

[1]. Grover S, State of consultation-liaison psychiatry in India: Current status and vision for future Indian J Psychiatry 2011 53:202-13.

[2]. Parekh HC, Deshmukh DK, Bagadia VN, Vahia NS, Analysis of indoor psychiatric referrals in a general hospital Indian J Psychiatry 1968 10:81-83

[3]. MakhalManabendra, MajumderUttam, Psychiatric comorbidity among refer of inpatients and need for Consultation Liaison Psychiatry. Delhi Psychiatry Journal Vol 16 No. 1, April 2013.

[4]. Boone CR, Coulton CJ, Keller SM. The impact of early and comprehensive social work services on length of stay. Soc Work Health Care 1981; 7: 1-9.

[5]. Saltz CC, Magruder-Habib K. Recognising depression in patient receiving medical care. Health Soc Work 1985; $10 ; 15-22$.

[6]. Grover S. State of consultation-liaison psychiatry in India: Current status and vision for future. Indian J Psychiatry. 2011; 53:20213.

[7]. N. Keertish, MT Sathyanarayana et al: Pattern of Psychiatric Referrals in a Tertiary Care Teaching Hospital in Southern India. Journal of Clinical and Diagnostic Research. 2013 Aug, Vol-7(8): 1689-1691. 
[8]. Bhogale GS, Katte RM, Heble SP, Sinha UK, Patil PA. Psychiatric referrals in multi- speciality hospital Indian J Psychiatry 2000 42:188-94.

[9]. Popkin MK, Mackenzie TB, Callies AL. Psychiatric Consultations to geriartric medically ill inpatients MA University hospital. Arch Gen Psychiatry 1984: 41:703-3.

[10]. Parekh HC, Deshmukh DK, Bagadia VN, Vahia NS. Analysis of indoor psychiatric referrals in a general hospital. Indian J Psychiatry 1968:10: 81-3.

[11]. Prabakaran N. Inpatient psychiatric referrals in a general hospital. Indian J Psychiatry 1968; 10;73-7.

[12]. Avasthi A, Sharan P, Kulhara P, Malhotra S, Varma VK. Psychiatry profiles in medical-surgical populations: need for a focused approach to consultation Liaison psychiatry in developing countries. Indian J Psychiatry 1998; 40; 224-30.

[13]. Jhanjee A, Kumar P, Srivastav S, Bhatia M.S. A Descriptive Study of Referral Pattern in Department of Psychiatry of A Tertiary Care Hospital of North India. Delhi Psychiatric Journal 2011;14 (1) 92-4

[14]. Dhavale HS, Barve RG, Psychiatric Referral Pattern in General Hospital. Journal of postgraduate medicine.1990;36 (4) 192-202

[15]. Peh LH, Tay WK, Psychiatry referral pattern in general hospital, Singapore Med J 1990: 31: 42-45

[16]. Chen CY, Yeh SS. The present state psychiatric consultation in Change Gung Memorial Hospital, Keelung: a report of clinical characteristics. Change-KengHsueh. 1996; 19(4):331-36

[17]. Aghanwa H. Consultation Liaison psychiatry in Fiji. Pacific Health Diag. 2002; 9(1):21-28

[18]. Law Commission of India, 201st report: Emergency Medical Care to victims of accidents and during emergency medical condition and women under labour. New Delhi; 2006 Aug

[19]. Singh PM, Vaidya L, Shrestha DM, Tajhya R, Shakya S, Consultation liaison psychiatry at Nepal Medical College and Teaching Hospital Nepal Med Coll J 2009 11(4):272-74

[20]. Chapagai M, Dangol KM, Ojha SP, Rana M, Tulachan PA Descriptive study of referral in Department of Psychiatry in Tertiary Hospital in Nepal J Psychiatrists' Association of Nepal Vol .2, No.2, 2013

[21]. MM Jalal Uddin1, MS JahirulHoque Chowdhury2, Md. Jahidul Islam et al Referral Pattern of Patients to Psychiatry Department at Neuroscience Institute in Bangladesh Journal of National Institute of Neurosciences Bangladesh, January 2015, Volume 1, Number 1

[22]. Malik M, Abbas N, Azad N. Psychiatric Morbidity in Medical and Surgical in Patients, Referred for Psychiatric Consultation. Journal of Rawalpindi Medical College 2008;12. 